\title{
Perfil bioquímico do líquido amniótico de éguas com placentite ascendente e sua relação com parâmetros séricos do potro neonato
}

Biochemical profile of amniotic fluid in mares with ascending placentitis and its relationship with serum biochemical parameters in neonatal foals

\section{Camila Gervini Wendt ${ }^{1}$; Carlos E. Wayne Nogueira ${ }^{1}$; Rafaela Bastos da Silva ${ }^{1}$, Ilusca Sampaio Finger $^{1}$; Lorena Soares Feijó ${ }^{1}$; Fernanda Maria Pazinato ${ }^{1}$; Nereu Carlos Prestes ${ }^{2}$; Bruna De Vita ${ }^{2}$; Bruna da Rosa Curcio ${ }^{*}$}

\author{
${ }^{1}$ Departamento de Clínicas Veterinárias, Faculdade de Veterinária, UFPel, Pelotas RS, Brasil \\ ${ }^{2}$ Universidade Estadual Paulista, UNESP, Botucatu, SP
}

\section{Resumo}

O objetivo do presente estudo foi identificar os parâmetros bioquímicos do líquido amniótico (LA) no momento do parto de éguas com placentite ascendente e relacionar com parâmetros bioquímicos séricos dos neonatos. Foram utilizadas 36 éguas gestantes da raça Puro Sangue Inglês, divididas em dois grupos: placentite $(n=5)$ e sadias $(n=31)$. A placentite foi definida de acordo com a avaliação clínica, exame ultrassonográfico e histopatologia das placentas. Essas éguas foram submetidas a terapia antimicrobiana, antiinflamatórios e altrenogest. A coleta do LA foi realizada na segunda fase do parto e as amostras sanguíneas dos neonatos imediatamente após o nascimento. Foi observada menor concentração de creatinina no LA de éguas com placentite. Potros provenientes de éguas com placentite foram menores em peso e altura ao nascimento, e apresentaram concentrações elevadas de ureia e reduzidas de PPT na avaliação sérica. Foi observado correlação positiva moderada entre creatinina e ureia no LA e correlação positiva fraca entre a creatinina do LA e sérica dos potros. Concluiu-se que o perfil bioquímico do LA e sérico dos neonatos oriundos de éguas com placentite ascendente diferem de gestações sadias. Sendo que esses parâmetros podem ser utilizados como indicadores de alterações placentárias em éguas.

Palavras-chave: gestação, creatinina, uréia, equinos.

\begin{abstract}
The aim of this study was to identify the biochemical parameters of amniotic fluid (AF) at parturition in mares with ascending placentitis, and to relate with biochemical parameters in neonatal foals' serum. Thirty-six pregnant Thoroughbred mares were divided in 2 groups: mares with placentitis $(n=5)$ and healthy mares $(n=31)$. Placentitis was identified based on clinical signs, ultrasound evaluation and histopathological features in the placenta. Mares with placentitis were treated with antibiotics, antiinflammatories and altrenogest. AF was collected during the second stage of labor and blood samples were taken immediately after foaling. Lower concentrations of creatinine were found in the AF of mares with placentitis. Foals from mares with placentitis showed smaller height and lower birthweight, also showed increase of urea and decrease of total protein levels in blood serum. A moderate positive correlation between urea and creatinine in AF was observed, and a weak positive correlation was found between creatinine in AF and the serum of foals. In conclusion, biochemical composition of AF and of blood serum of neonatal foals from mares with ascending placentitis are different of healthy mares. So, those analysis could be useful to identify placental changes in mares.
\end{abstract}

Key words: gestation, creatinine, urea, equine.

\section{Introdução}

Em equinos, assim como nos demais mamíferos domésticos, as funções vitais para o desenvolvimento e a manutenção da vida fetal como a oxigenação, nutrição e excreção são realizadas através de trocas placentárias (Ginther, 1998; Prestes, 2006), por isso alterações nesta estrutura afetam diretamente o desenvolvimento e bem-estar fetal (Wilsher et al., 2005). O líquido amniótico envolve o feto durante a gestação desempenhando papel fundamental para a proteção fetal no ambiente intrauterino,

${ }^{1}$ Correspondência: curciobruna@hotmail.com Recebido: 05 de setembro de 2019

Aceito: 21 de agosto de 2020 
Wendt et al. Perfil bioquímico do líquido amniótico de éguas com placentite ascendente e sua relação com parâmetros séricos do potro neonato

auxilia na lubrificação no momento do parto (Asbury e Leblanc, 1993), e ainda, pode refletir a condição materno fetal tanto por sua composição como pelo seu volume (Dertkigil et al., 2005).

O volume de fluídos fetais na égua é cerca de 10-12 litros no final da gestação, sendo esse volume regulado basicamente pela excreção e deglutição do feto (Williams et al., 1993). O líquido amniótico possui característica viscosa sendo derivado da pele, mucosas e das secreções naso-faríngeas, enquanto o fluido alantoide consiste basicamente no produto de excreção dos rins fetais (Baetz et al., 1976). Os componentes bioquímicos do líquido amniótico (LA) podem estar alterados em algumas situações de sofrimento fetal em equinos, sendo já descrito diferenças nas concentrações de lactato (Pirrone et al., 2012), bilirrubinas e fosfatase alcalina (Kochhar et al., 1997) de éguas que sofreram parto distócico. Em humanos, as concentrações de determinados componentes do LA são consideradas marcadores para maturidade e prognóstico de viabilidade neonatal (Begneaud et al, 1969; Parmley e Miller, 1969).

A causa mais frequente de perdas gestacionais tardias em equinos é a placentite (Giles et al., 1993). Esta alteração causa comprometimento da unidade útero-feto-placentária que interfere na difusão de moléculas entre as circulações materna e fetal, reduzindo o aporte de nutrientes e oxigênio para o feto e a placenta (Rossdale, 2004). Consequências desses danos placentários podem promover o aborto, o nascimento de um natimorto ou de um potro extremamente debilitado ou paradoxalmente com poucas alterações clínicas (Bain, 2004).

A identificação de alterações na avaliação sérica em potros neonatos provenientes de gestações com placentite e outras disfunções placentárias já está estabelecida (Pirrone et al., 2014; Feijó et al., 2018). Recentemente, alterações na proteomica do LA amniótico de éguas submetidas a indução experimental de placentite também foram identificadas, incluindo o up-regulation de hatoglobina e plasminogênio (Loux e Ball, 2018). No entanto, ainda pouco se sabe como os componentes bioquímicos do LA se comportam em alterações placentárias e qual sua relação com as avaliações bioquímicas séricas do neonato (Pirrone et al., 2012).

Assim, o objetivo deste estudo foi identificar os parâmetros bioquímicos do LA no momento do parto de éguas com placentite e correlacionar com a avaliação bioquímica sérica dos potros neonatos provenientes dessas éguas.

\section{Material e métodos}

Para a realização deste estudo foram utilizadas 36 éguas gestantes da raça Puro Sangue Inglês e seus respectivos potros. Estas estavam alocados em um criatório no município de Aceguá, Rio Grande do Sul, apresentando idade entre 5 e 21 anos. Todos os procedimentos realizados nos animais foram aprovados pela Comissão de Ética em Experimentação Animal (CEEA) da Universidade Federal de Pelotas, sob o número de protocolo 23110.005008/2013-43.

\section{Monitoramento dos animais}

As éguas eram inspecionadas diariamente durante todo o período gestacional, sendo observadas quanto ao aparecimento de sinais clínicos de placentite, Mensalmente era realizado exame obstétrico por palpação e ultrassonografia transretal, com o uso de transdutor linear 5-MHz (SonoVet600, Medison Co. Ltd, Seul, KR). A partir do $5^{\circ}$ mês de gestação, durante o exame ultrassonográfico transretal, avaliava-se o espessamento da junção útero placentária (JUP) na porção caudal da placenta, além da presença de exsudato ou de separação do córioalantóide do endométrio (Bucca et al., 2005). A avaliação da JUP era realizada conforme descrito por Renaudin et al. (1997), sendo considerado valores normais menores que $8 \mathrm{~mm}$ entre 271-300 dias de gestação, até $10 \mathrm{~mm}$ entre os dias 301-330, e menores que $12 \mathrm{~mm}$ a partir dos 330 dias de gestação.

Foram utilizadas no presente estudo éguas diagnosticadas com placentite no período entre 280300 dias de gestação. As mesmas foram tratados com Sulfa-trimetoprim (Trissulfinß, Ouro Fino Agronegócio, Brasil), na dose $30 \mathrm{mg} / \mathrm{kg}$, endovenoso, a cada 12 horas, durante 10 dias, Flunixin meglumine (Desflan ${ }^{\circledR}$, Ouro Fino Agronegócio, Brasil), na dose $1,1 \mathrm{mg} / \mathrm{kg}$, endovenoso, a cada 24 horas, e Altrenogest (Regu-Mate ${ }^{\circledR}$, Merck Animal Health, EUA) na dose de $0,088 \mathrm{mg} / \mathrm{kg}$, oral, a cada 24 horas. Somente a administração de Altrenogest permaneceu de forma continuada até os 320 dias de gestação. Por serem éguas de um criatório particular com desenvolvimento espontâneo de placentite, não forma realizados exames microbiológicos para identificação do agente etiológico, antes de iniciar a 
Wendt et al. Perfil bioquímico do líquido amniótico de éguas com placentite ascendente e sua relação com parâmetros séricos do potro neonato

antibioticoterapia.

Trinta dias antes da data de previsão do parto todas as éguas eram direcionadas para o piquete de parição e mantidas sob constante observação para a realização do parto assistido.

\section{Coleta de amostras}

Após o rompimento do alantocórion e exposição da membrana amniótica, as éguas eram conduzidas para baias maternidade para que o parto fosse assistido. A coleta do LA era realizada através da punção direta da vesícula amniótica no momento da sua exposição, com o uso de uma seringa de $20 \mathrm{ml}$ e agulha $(40 \times 12 \mathrm{~mm})$. O material era imediatamente transferido para tubos Falcon ${ }^{\circledR}$ de $15 \mathrm{ml}$ e armazenado em freezer à temperatura de $-20^{\circ} \mathrm{C}$ para posterior avaliação bioquímica.

Após o nascimento foi realizada a pesagem (balança comercial digital) e aferição da altura na cernelha (hipômetro) dos potros. As amostras séricas dos neonatos eram colhidas imediatamente após o nascimento, sendo realizadas através da punção da veia jugular em dois tubos: um com ativador de coágulo e um com anticoagulante EDTA. Após a coleta era realizada a centrifugação dos tubos com ativador de coágulo a 2200 RPM para a obtenção do soro e as amostras de soro mantidas em eppendorfs de $2 \mathrm{ml}$ em freezer $-20^{\circ} \mathrm{C}$ para posterior avaliação.

\section{Avaliação placentária}

As placentas eram pesadas e dispostas em formato de "F" imediatamente após a expulsão. Na avaliação macroscópica, ambas as faces eram inspecionadas quanto a presença de exsudatos na face coriônica, ausência de vilosidades, alterações de coloração, ou áreas de espessamento, conforme descrito por Schlafer (2004). Para a análise histopatológica, foram coletados sete fragmentos de $3 \times 3 \mathrm{~cm}$ de diâmetro de cada diferentes pontos da placenta, sendo estes correspondentes a: estrela cervical, corpo uterino, corno gravídico e não gravídico, bifurcação, âmnion e cordão umbilical. Os fragmentos foram armazenados em tubos Falcon ${ }^{\circledR}$ de $50 \mathrm{ml}$ acrescidos de solução de formalina tamponada a $10 \%$ para fixação. $\mathrm{Na}$ avaliação microscópica, avaliou-se a integridade do epitélio corioalantóide, disposição dos microcotilédones, presença de alterações nos componentes da membrana corioalantóide, como infiltrados inflamatórios, edema, necrose ou hipoplasia dos microcotilédones (Pazinato et al., 2016). Os diagnósticos de placentite foram confirmados através da presença de infiltrado inflamatório em, no mínimo, três pontos avaliados.

\section{Divisão de grupos}

Foram classificadas como placentite $(n=5)$ éguas que apresentaram sinais clínicos característicos entre 280-300 dias de gestação, sendo eles: secreção vulvar, desenvolvimento precoce do úbere e/ou galactorréia; e no exame ultrassonográfico transvaginal apresentaram: espessamento da JUP, descolamento do corioalantóide e presença de exsudato. O diagnóstico foi ainda confirmado devido a presença de alteração na avaliação macroscópica e infiltrado supurativo na avaliação histopatológica da placenta no pós-parto (Hong et al., 1993; Pazinato et al., 2016). Enquanto as éguas sadias (n=31) não apresentaram sinais clínicos ou achados ultrassonográficos de placentite durante a gestação. As éguas sadias não apresentaram alterações nas avaliações macroscópica da placenta, sendo observado padrão normal de integridade dos microcotilédones e ausência de infiltrados leucocitários na avaliação histopatológica das mesmas (Pazinato et al., 2016).

\section{Análises bioquímicas}

As análises bioquímicas do LA foram realizadas no laboratório de patologia clínica da Faculdade de Medicina Veterinária e Zootecnia da UNESP/Botucatu, similar ao descrito por Zanella et al. (2014). Foram avaliados $\mathrm{pH}$, fosfatase alcalina (FA), gamma - GT, ureia, creatinina, sódio (Na), potássio $(\mathrm{K})$, cloretos $(\mathrm{Cl})$, cálcio $(\mathrm{Ca})$, osmolaridade e proteína total $(\mathrm{PT})$. A quantificação foi realizada com espectrofotômetro, SB - 190 Celm (Companhia Equipadora de Laboratórios Modernos, Barueri, São Paulo, SP, Brasil), para todos os elementos, exceto sódio e potássio, que foram avaliados com auxílio do equipamento CELM FC - 280 Fotômetro de chama (Companhia Equipadora de Laboratórios Modernos).

Já as análises da bioquímica sérica foram realizadas na Universidade Federal de Pelotas, 
Wendt et al. Perfil bioquímico do líquido amniótico de éguas com placentite ascendente e sua relação com parâmetros séricos do potro neonato

UFPel. Foram utilizados kits comerciais (Labtest Diagnóstica SA, Lagoa Santa, Brasil) para quantificação dos parâmetros ureia, creatinina e glicose através de espectofotometria. Os coeficientes de variação entre as análises foram menores que $10 \%$. As medições de fibrinogênio e proteína plasmática total foram realizadas por refratometria, a partir da amostra de sangue em EDTA, logo após a coleta no próprio criatório.

Análise estatística

A análise estatística foi realizada com auxílio do software Statistix 10.0® (Analytical Software, Tallahassee, FL, USA). Foi utilizado o teste de t-two Sample para realizar a comparação de médias, e teste de Pearson para avaliar a correlação entre as variáveis. Os valores estão expressos em média \pm erro padrão da média.

\section{Resultados}

O peso da placenta e tempo médio de gestação não diferiram entre os grupos de éguas com placentite e sadias, sendo respectivamente $5,8 \pm 0,2 \mathrm{Kg}$ vs $6,7 \pm 0,6 \mathrm{Kg}$ e $335,20+5$ dias vs $345,32 \pm 2$ dias ( $\mathrm{p}>0,05)$. Os potros nasceram viáveis, não sendo necessário qualquer tipo de intervenção clínica após o nascimento. Contudo potros provenientes de éguas com placentite foram menores em peso e altura, do que potros de éguas saudáveis, sendo respectivamente $49 \pm 1,1 \mathrm{Kg}$ e $0,99 \pm 0,03 \mathrm{~m}$ vs $56,7 \pm 6,2 \mathrm{Kg}$ e $1,04 \pm 0,03 \mathrm{~m}(\mathrm{p}<0,05)$.

$\mathrm{Na}$ análise bioquímica do líquido amniótico (Tab. 1) foi observada menor concentração de creatinina no líquido proveniente de éguas com placentite $(\mathrm{p}=0,004)$. Já na avaliação bioquímica sérica dos neonatos, o grupo oriundo de gestações com placentite apresentou incremento nos valores de ureia $(\mathrm{p}=0,016)$ (Tab. 2). Foi observada correlação positiva moderada $(\mathrm{r}=0,56, \mathrm{p}<0,001)$ entre creatinina e ureia no LA e correlação positiva fraca $(r=0,38, p=0,024)$ entre a creatinina do LA e creatinina sérica dos potros. Entre os demais parâmetros avaliados não foram identificadas correlações.

Tabela 1. Avaliação bioquímica do líquido amniótico (LA) de éguas puro-sangue inglês a termo (éguas sadias e com placentite)

\begin{tabular}{ccc}
\hline Bioquímica LA & $\begin{array}{c}\text { Sadias }(\mathbf{n}=\mathbf{3 1}) \\
\text { Média } \pm \mathbf{E P M}\end{array}$ & $\begin{array}{c}\text { Placentite }(\mathbf{n}=\mathbf{5}) \\
\text { Média } \pm \mathbf{E P M}\end{array}$ \\
\hline $\mathrm{pH}$ & $7,70 \pm 0,03^{\mathrm{a}}$ & $7,72 \pm 0,1^{\mathrm{a}}$ \\
Sódio $(\mathrm{mEq} / \mathrm{L})$ & $54,35 \pm 2,51^{\mathrm{a}}$ & $51,60 \pm 2,73^{\mathrm{a}}$ \\
Potássio $(\mathrm{mEq} / \mathrm{L})$ & $1,71 \pm 0,12^{\mathrm{a}}$ & $2,08 \pm 0,30^{\mathrm{a}}$ \\
Cálcio $(\mathrm{mg} / \mathrm{dL})$ & $3,86 \pm 0,23^{\mathrm{a}}$ & $3,7 \pm 0,52^{\mathrm{a}}$ \\
Cloretos $(\mathrm{mEq} / \mathrm{L})$ & $72,09 \pm 5,94^{\mathrm{a}}$ & $62,20 \pm 3,35^{\mathrm{a}}$ \\
Fosfatase Alcalina (UI/L) & $30,45 \pm 2,68^{\mathrm{a}}$ & $31,0 \pm 2,3^{\mathrm{a}}$ \\
Gamma $-\mathrm{GT}(\mathrm{UI} / \mathrm{L})$ & $4,66 \pm 0,62^{\mathrm{a}}$ & $3,42 \pm 0,43^{\mathrm{a}}$ \\
Ureia $(\mathrm{mg} / \mathrm{dL})$ & $33,59 \pm 2,34^{\mathrm{a}}$ & $34,26 \pm 4,52^{\mathrm{a}}$ \\
Creatinina $(\mathrm{mg} / \mathrm{dL})$ & $5,10 \pm 0,59^{\mathrm{a}}$ & $2,88 \pm 0,38^{\mathrm{b}}$ \\
Osmolaridade $(\mathrm{mOsml} / \mathrm{L})$ & $277,32 \pm 17,77^{\mathrm{a}}$ & $258,20 \pm 28,79^{\mathrm{a}}$ \\
Proteína Total $(\mathrm{mg} / \mathrm{dL})$ & $26,04 \pm 4,39^{\mathrm{a}}$ & $21,32-4,70^{\mathrm{a}}$
\end{tabular}

Letras diferentes na linha denotam diferença pelo teste t-two sample $(\mathrm{p}<0,05)$.

Tabela 2. Média, Erro Padrão dos componentes bioquímicos séricos dos potros no momento do nascimento de acordo com os grupos de éguas sadias e com placentite.

\begin{tabular}{ccc}
\hline Bioquímica Sérica & Sadias $(\mathbf{n}=\mathbf{3 1})$ & Placentite $(\mathbf{n}=\mathbf{5})$ \\
\hline Ureia $(\mathrm{mg} / \mathrm{dL})$ & $83,60 \pm 2,21^{\mathrm{b}}$ & $100,47 \pm 7,71^{\mathrm{a}}$ \\
Creatinina $(\mathrm{mg} / \mathrm{dL})$ & $3,02 \pm 0,16^{\mathrm{a}}$ & $2,58 \pm 0,19^{\mathrm{a}}$ \\
Glicose $(\mathrm{mg} / \mathrm{dL})$ & $113,16 \pm 8,8^{\mathrm{a}}$ & $121,9 \pm 6,04^{\mathrm{a}}$ \\
Proteína total $(\mathrm{g} / \mathrm{dL})$ & $6,5 \pm 0,11^{\mathrm{a}}$ & $5,82 \pm 0,16^{\mathrm{b}}$ \\
Fibrinogênio $(\mathrm{mg} / \mathrm{dL})$ & $303,23 \pm 21,49^{\mathrm{a}}$ & $300 \pm 44,72^{\mathrm{a}}$ \\
\hline
\end{tabular}

Letras diferentes nas linhas denotam diferença pelo teste t-two sample $(p<0,05)$. 
Wendt et al. Perfil bioquímico do líquido amniótico de éguas com placentite ascendente e sua relação com parâmetros séricos do potro neonato

\section{Discussão}

Neste estudo, as éguas com placentite apresentaram redução da concentração de creatinina no líquido amniótico, em relação ao encontrado em éguas sadias. Sendo que potros neonatos provenientes das éguas com placentite foram menores ao nascimento e apresentaram na avaliação bioquímica sérica incremento de uréia e redução da PPT. Sugerindo que estes parâmetros estejam associados a alterações placentárias e redução no crescimento dos potros, mesmo com o nascimento de neonatos viáveis.

A composição do LA está relacionada a atividade de órgãos fetais por circular nos pulmões, estômago e intestino, promovendo o transporte de metabólitos para a cavidade amniótica (Gulbis et al., 1998). Os valores de creatinina no LA apresentam um padrão crescente durante as fases gestacionais em éguas (De Vita et al., 2014; Zanella et al., 2014). Em humanos, este aumento é atribuído à maturidade do sistema urinário e ao incremento de massa muscular fetal (Begneaud et al., 1969), em equinos, também é sugerido que seja reflexo da maturidade do sistema urinário fetal (Williams et al., 1993). Assim, baixas concentrações de creatinina no LA de gestações de risco estão relacionadas ao nascimento de bebês imaturos, com menor peso e menores taxas de sobrevivência (Begneaud et al., 1969), o que pode ser identificado também no presente estudo com potros neonatos menores ao nascimento.

Os valores de $\mathrm{K}, \mathrm{Cl}$, PT, GGT e ureia no LA não diferiram entre os grupos e foram similares ao fisiológico descrito por De Vita et al. (2014) no momento do parto, assim como a concentração de creatinina do grupo de éguas sadias

No presente estudo foram avaliadas as concentrações séricas de creatinina, ureia, fibrinogênio e glicose dos neonatos, já que esses parâmetros são relacionados à eficiência placentária em potros neonatos (Pirrone et al., 2014). Ambos os grupos apresentaram valores mais elevados de ureia que o padrão de referência (Aoki e Ishii, 2012), no entanto, entende-se que essa é uma característica desta população, tendo em vista que os resultados foram similares aos já descritos com animais do mesmo local (Lins, et al. 2012; Feijó et al., 2018). O grupo placentite apresentou valores séricos mais elevados de ureia e reduzidos de PPT ao nascimento. Essas alterações ao nascimento estão relacionadas ao catabolismo proteico fetal, devido à falta de substratos energéticos (Pirrone et al., 2014). Outra hipótese para esses achados, incremento de uréia e redução de PPT, pode ser atribuída a imaturidade hepática que está relacionada com a falha na maturação orgânica comum em potros neonatos que sofreram intercorrências durante a gestação, como descrito por Stoneham (2006).

Pouco se sabe a respeito da dinâmica dos componentes bioquímicos do LA em alterações placentárias ou de sua relação com parâmetros neonatais em equinos. As concentrações de creatinina no LA das éguas com placentite apresentaram fraca correlação $(r=0,38, p=0,0242)$ com os valores séricos desse metabólito. A hipercreatinemia ocorre em potros neonatos que sofreram com a insuficiência placentária e apresentam imaturidade marcada (Morresey, 2005; Chaney et al., 2010), enquanto os potros maturos nessa situação apresentam valores normais de creatinina sérica (Feijó et al., 2018).

Diferenças relacionadas a viabilidade dos potros das éguas com placentite está relacionada à capacidade de alterações infecciosas ou inflamatórias da unidade feto-placentária promoverem ativação prematura do eixo hipotálamo-hipófise-adrenal fetal, (Canisso et al., 2015), promovendo a antecipação da maturação geral dos neonatos. No presente estudo, o tratamento das éguas com associação de antibiótico, anti-inflamatório e hormônios para a placentite ascendente permitiu a manutenção da gestação a termo, caracterizada pelo tempo de gestação e peso das placentas que não diferiram das éguas saudáveis. Isso também corroborou para o nascimento de potros viáveis, contudo esses apresentaram menor peso e altura ao nascimento e imaturidade hepática na avaliação da bioquímica sérica. Mesmo com a realização do tratamento clínico para a placentite durante a gestação, a confirmação da permanência de lesões até o momento do parto foi confirmada na avaliação placentária após expulsão. Éguas do grupo placentite apresentaram alterações macroscópicas características e infiltrado supurativo na avaliação histopatológica, as quais são descritas por Hong et al. (1993) e Pazinato et al. (2016).

\section{Conclusão}

O perfil bioquímico do LA e sérico dos neonatos oriundos de éguas com placentite ascendente diferem de gestações sadias. A creatinina do LA foi menor em éguas com placentite e os potros provenientes dessas éguas apresentaram redução da proteína plasmática total e elevação da ureia sérica, não havendo correlação entre estes parâmetros. Assim, os parâmetros bioquímicos do LA podem ser utilizados como indicadores de alterações placentárias em éguas. 
Wendt et al. Perfil bioquímico do líquido amniótico de éguas com placentite ascendente e sua relação com parâmetros séricos do potro neonato

\section{Agradecimentos}

Os autores agradecem ao Centro Agropecuária da Palma pelo auxílio para manutenção dos animais e as agências de fomento CAPES, FAPERGS e CNPQ pelo apoio ao desenvolvimento de nossas atividades científicas e financiamento de bolsas para alunos de graduação e pós-graduação em Veterinária - PPGV - UFPel.

\section{Referências}

Asbury AC, Leblanc MM. The placenta. In: McKinnon AO, Voss JL. Equine reproduction. 1st ed. Pennsylvania: Lea e Febiger, English, p.509-516, 1993.

Aoki T, Ishii M. Hematological and biochemical profiles in peripartum mares and neonatal foals (heavy draft horse). J Equine Vet Sci, v.32, n.3, p.170-176, 2012.

Baetz AL, Hubert WT, Graham CK. Changes of biochemical constituents in bovine fetal fluids with gestational age. Am J Vet Res, v.37, n.9, p.1047-1052, 1976.

Bain FT. Management of the foal from the mare with placentitis: A clinician's approach. In: Proceedings of the 50th Annual Meeting of the American Association of Equine Practitioners, Doc Number 1419.1204, 2004.

Begneaud WP Jr, Hawes TP Jr, Mical A, Samuels M. Amniotic Fluid Creatinine for Prediction of Fetal Maturity. Obstet Gynecol, v.34, n.1, p.7-13, 1969.

Bucca S, Fogarty U, Collins A, Small V. Assessment of feto-placental well-being in the mare from midgestation to term: transrectal and transabdominal ultrasonographic features. Theriogenology, v.64, p.54257, 2005.

Canisso IF, Ball BA, Erol E, Squires EL, Troedsson MHT. Comprehensive review on equine placentitis. In: Proceedings of the 61th Annual Meeting of the American Association of Equine Practitioners, p.490-509, 2015.

Chaney KP, Holcombe SJ, Schott HC, Barr BS. Spurious hypercreatininemia: 28 neonatal foals (20002008). J Vet Emerg Crit Care, v.20, p.244-249, 2010.

De Vita B, Campos LL, Listoni JA, Martin I, Takahira RK, Curcio BR, Landim-Alvarenga FC, Prestes NC. Comparação da composição bioquímica do líquido amniótico equino colhido em diferentes estágios gestacionais e no momento do parto. Pesq Vet Bras, v.34, p.582-588, 2014.

Dertkigil MS, Cecatti JG, Cavalcante SR, Baciuk EP, Bernardo AL. Líquido Amniótico, atividade física e imersão em água na gestação. Rev Bras Saúde Mater Infant, v.5, p.403-10, 2005.

Feijó LS, Curcio BR, Pazinato FM, Almeida BA, Moraes BSS, Borba LA, Feijó JO, Nogueira CEW. Hematological and biochemical indicators of maturity in foals and their relation to the placental features. Pesq Vet Bras, v.38, p.1232-1238, 2018.

Giles RC, Donahue JM, Hong CB, Tuttle PA, Petrites-Murphy MB, Poonacha KB, Roberts AW, Tramontin RR, Smith B, Swerczek TW. Causes of abortion, stillbirth, and perinatal death in horses: 3,527 cases (1986-1991). J Am Vet Med A, v.203, p.1170-75, 1993.

Ginther OJ. Equine Pregnancy: Physical Interactions Between the Uterus and Conceptus. In: In: Proceedings of the 44th Annual Meeting of the American Association of Equine Practitioners, p.73-104, 1998.

Gulbis B, Gervy C, Jauniaux E. Amniotic fluid biochemistry in second-trimester trisomic pregnancies: relationships to fetal organ maturation and dysfunction. Early Hum Dev, v.52, p.211-19, 1998.

Hong CB, Donahue JM, Giles RC, Petrites-Murphy MB Jr, Poonacha KB, Roberts AW, Smith BJ, Tramontin RR, Tuttle PA, Swerczek TW. Etiology and pathology of equine placentites. J Vet Diagn Invest. v. 5, p.55-63, 1993.

Stoneham SJ. Assessing the newborn foal. In: Paradis MR. Equine Neonatal Medicine: A Case-Based Approach. 1st ed. Philadelphia: Elsevier Saunders. English, p.1-11, 2006.

Kochhar HPS, Simran PS, Ripudaman K. Comparative Biochemical indices of fetal fluids in normal foaling and stressful delivery in Indian thoroughbred mares. J Equine Vet Sci, v.17, p.206-210, 1997.

Lins LA, Finger IS, Fernandes CG, Curcio BR, Corrêa MN, Nogueira CEW. Resposta clínica e metabólica de potros neonatos em relação aos achados histopatológicos da placenta na égua. Arq Bras Med Vet Zootec, v.64, p.1436-1441, 2012.

Loux SC, Ball BA. The proteome of fetal fluids in mares with experimentally-induced placentitis. Placenta, v.64, p.71-78, 2018. 
Wendt et al. Perfil bioquímico do líquido amniótico de éguas com placentite ascendente e sua relação com parâmetros séricos do potro neonato

Morresey PR. Prenatal and perinatal indicators of neonatal viability. Clin Tech Equine Pract, v.4, p.238249, 2005.

Pazinato FM, Curcio BR, Fernandes CG, Feijó LS, Schmith RA, Nogueira CEW. Histological features of the placenta and their relation to the gross and data from Thoroughbred mares. Pesq Vet Bras, v.36, p.665-670, 2016.

Pirrone A, Mariella J, Gentilini F, Castagnetti C. Amniotic fluid and blood lactate concentrations in mares and foals in the early postpartum period. Theriogenology, v.78. p.1182-1189, 2012.

Pirrone A, Antonelli A, Mariella J, Castagnetti C. Gross placental morphology and foal serum biochemistry as predictors of foal health. Theriogenology, v.81, p.1293-1299, 2014.

Prestes N.C. Os líquidos fetais e sua constituição bioquímica. In: Prestes NC, Landim-Avarenga FC. Obstetrícia Veterinária. 1.ed. Rio de Rio de Janeiro: Guanabara-Koogan, p.41-51, 2006.

Renaudin CD, Troedsson MHT, Gillis CL, King VL, Bodena A. Ultrasonographic evaluation of the equine placenta by transrectal and transabdominal approach in the normal pregnant mare. Theriogenology, v.47, p.559-673, 1997.

Rossdale PD. The maladjusted foal: influences of intrauterine growth retardation and birth trauma. In: Proceedings of the 50th Annual Meeting of the American Association of Equine Practitioners, p.75-126, 2004.

Schlafer DH. Postmortem examination of the equine placenta, fetus, and neonate: Methods and interpretation of findings. In: Proceedings of the 50th Annual Meeting of the American Association of Equine Practitioners, p.144-161, 2004.

Williams MA, Wallace SS, Tyler JW, Mccall CA, Gutierrez A, Spano JS. Biochemical characteristics of amniotic and allantoic fuid in late gestational mares. Theriogenology, v.40, n.6, p.1251-1257, 1993.

Wilsher S, Ousey J, Allen WR. Gross and histological observation on placentae from abnormal pregnancies. In: Proc. Workshop on Comparative Placentology in Havemeyer Foundation Monograph Series, v.17, p.57-58, 2005.

Zanella LF, Takahira RK, Melo CM, Magalhães OLC, Prestes NC. Biochemical profile of amniotic and allantoic fluid during different gestational phases in mares. J Equine Vet Sci, v.34, p.403-406, 2014. 